\title{
CONSUMERS' FOOD CHOICES AND THE ROLE OF PERCEIVED ENVIRONMENTAL IMPACT
}

\author{
S. WUNDERLICH \& K.A. GATTO \\ Department of Health and Nutrition Sciences, Montclair State University, Montclair, NJ USA
}

\begin{abstract}
As the world population grows to a predicted 9 billion people by 2050 , food availability and security should be considered, and the relationship between food production and consumers' selection of their food may influence the global agriculture system and perhaps the environment. In an altruistic sense, purchase of sustainable foods is strongly correlated with the measures of ethical self-identify, moral attitude, concern for environmental issues, and other measures of global concern. Additional analysis of values in relation to environmental purchasing and policy similarly found that intention to purchase environmentally friendly products is positively correlated with food and environmental concerns. While this ethical vision of making sustainable or organic food choices is often viewed as altruistic, it can also be viewed as an egoistic motivator, as it relates to personal identification as an ethical person. Food choice is driven by other egoistic values as well, including nutritious qualities, sensory qualities, and overall health effects of food purchases. Attitudes toward genetically modified foods, which are not organic and are viewed as non-environmentally friendly, has been correlated with decreased purchasing behavior, indicating that the tie between attitudes towards certain food production methods can predict actual purchasing. Current research examines the complex relationship between consumer knowledge and purchasing behavior relating to multiple food production methods, including organic, genetically modified, and conventional.
\end{abstract}

Keywords: consumer, environment, ethical value, food choices, food production system, genetically modified organism, organic.

\section{INTRODUCTION}

The subject of food accessibility and food security for the growing world population is becoming increasingly important. The question of whether there will be enough food for 9 billion people in 2050 remains unanswered. Therefore, new systems of food production emerge on the basis of the theory that there should be more food produced in limited space to meet this demand. One of the food production systems designed to meet this need is the production of genetically modified organisms (GMOs), which is increasingly becoming an integral part the food we consume. According to the U.S. Food and Drug Administration, a genetically modified organism is one that has added characteristics that provide some type of benefit, such as increased growth and yield or improved nutritional value [1]. Foods produced through non-organic methods, or conventional foods, often contain GMOs [2]. Conversely, organic food is produced through methods that preserve ecological balance and biodiversity without the use of synthetic fertilizers, sewage sludge, irradiation, and genetic modification, meaning that $100 \%$ organic products do not contain GMOs or just GM (genetically modified) ingredients [3]. Since 1994 when the first GMO food (Flavr Savr tomatoes) appeared in on supermarket shelves, consumers have been offered foods that either contain GMO or are produced by this method. 
164 Environmental and Economic Impact on Sustainable Development

Consumers often select their foods based on specific motive(s). There are several factors that influence consumers' food selection, with people choosing the most personally salient reasons for individual purchasing motivation. Among these factors are: wholesomeness and nutritional value, cost, and most recently the production methods (organic, GMO), as well as possible environmental impact and ethical value.

\section{CONSUMER KNOWLEDGE ABOUT GM FOODS AND SOURCES OF INFORMATION}

Currently, consumer knowledge and understanding of GM food is insufficient, according to several published studies. Therefore, consumers are very cautious when it comes to GMOs, with one study reporting that over $70 \%$ believe that GM-food production is unsafe for all living things, and it could be dangerous to consume GMOs [4]. A study conducted at the Rutgers University Food Policy Institute indicated that consumers as a whole were fairly unknowledgeable about GMOs, with just $48 \%$ knowing that GMOs are available in supermarkets and only $31 \%$ believing that they had most likely consumed food that contained GMO products [5].

One possible reason for consumers' confusions and hesitation is that they may obtain their knowledge from unreliable, popular, and often nonscientific sources such as the Internet, television, and radio. In one study, just $13.6 \%$ used scientific papers to acquire information about the food products [6]. Some analysis showed that higher levels of scientific knowledge were significantly associated with the acceptance of the genetic modification technology for medical uses, GMO foods, and animal feed applications [7]. A review of consumer perception of genetic modification revealed that many consumers are not only poorly informed but are also dissatisfied with their level of understanding regarding GMOs [8]. Knowledge and understanding of GMO food and other bioengineering products may affect consumer attitude and, consequently, food purchasing behavior. Therefore, providing accurate, truthful information on food products is the most central medium for consumers to select their foods according to their health and ethical beliefs.

Today, a variety of these GM crops, namely corn, soybeans, canola, cotton, and alfalfa sprouts, are incorporated into food products on the market, but the prevalence of these GM foods differs from country to country. Consumer concerns over the safety of GM foods have led to the adoption of various policies regarding GMOs in countries worldwide. This paper seeks to examine how the environmental factors related to food production play a role in consumer food selection.

\section{ALTRUISTIC FACTORS}

\subsection{Ethical values and intent to purchase}

Altruism, which encompasses overall concern for the world, appears to be tied to sustainable and organic food production methods that work to preserve the world's environment while yielding high food production. Surveys of consumers purchasing food at farmers' markets or organic stores revealed that ethical self-identity $(r=0.61, p<0.01)$, or the personal view that oneself acts as an ethical consumer, could predict likelihood of purchasing sustainably sourced foods, which included organic production, animal welfare, and local producers (Dowd \& Burke, 2013). The second majorly contributing factor was positive moral attitude $(\mathrm{r}=0.73, \mathrm{p}<0.01)$, measured by reported feelings of contributing to the greater good through 
consumer actions. Together, ethical self-identity and moral attitude explain $11.3 \%$ of the predictive power, while traditional constructs of the Theory of Planned Behavior (such as attitude and subjective norms) predict $62 \%$ of variance. Measures of health value $(r=0.21$, $\mathrm{p}<0.05)$ and ethics $(\mathrm{r}=0.30, \mathrm{p}<0.05)$, which encompasses domains such as organic production and the value of local producers, were also correlated with intent to purchase sustainable foods in a small but significant way [9].

Research reveals that egoistic motives play a simultaneous role and influence food choice along with altruism. Egoistic factors like nutritious value $(\beta=0.69)$ and natural content ( $\beta=0.66)$ predict organic food beliefs, while altruistic factors like environmental effect also impact organic food beliefs (0.74). Such organic food belief is strongly related to organic food attitude $(\beta=0.75)$, which in turn is related to purchasing intent $(\beta=0.36)$. However, in a separate portion of the same investigation, researchers presented participants with an egocentric advertisement, an altruistic advertisement, and an advertisement combining both appeals. Participants reported stronger purchase intention when viewing the combined ad than the egoistic ad and control ad, but the altruistic ad resulted in similarly strong purchase intent, indicating that altruistic motivators are remarkably strong [10].

\subsection{Environmental concern and consumer purchasing}

Studies examining public opinion regarding environmental purchasing and policy also explore the relationship between intent to purchase environmentally friendly products and various ethical values. The majority of the surveyed group supported environmental policies (50\%-78\% support) and pro-environment food purchasing (51\%-69\%). Environmentally conscious purchasing intention was positively correlated with food and environmental concerns (std. Beta $=0.24, \mathrm{p}<0.01$ ), measured by the level of concern about various environmental issues, and universalism (std. Beta $=0.25, \mathrm{p}<0.01$ ), measured by the level of perceived importance of issues like equality, world peace, tolerance of beliefs, and social justice. Additional factors of lesser but still significant impact included concerns about nutrition (std. Beta $=0.13, \mathrm{p}<0.01$ ), food safety concerns ( std. Beta $=0.19, \mathrm{p}<0.01$ ), female gender ( std. Beta $=.05, \mathrm{p}<0.01$ ), and education ( std. Beta $=.17, \mathrm{p}<0.01$ ) [11].

Attitude towards genetically modified foods varies slightly more than attitude towards organic foods; organic production is generally agreed to be a safe and desirable method, while genetic modification is more controversial. Review of European countries reveals that they generally find GMOs to be environmentally hazardous and potentially dangerous for the future if consequences are not adequately assessed and remedied. GM food is generally viewed as morally unacceptable throughout Europe, though GM plants and enzymes are not as problematic. When responses were analyzed to find predictive significance, acceptance of GMOs was higher amongst those with science-based knowledge, younger populations, and those in the UK and Spain, where GM foods is supported economically and politically [12]. Additional research supports the fact that public opinion of GMOs can be predicted by features such as socioeconomic background, knowledge, and scientific background, while perception of the potential environmental impact impacts opinion of the use of such modification [13].

\subsection{Labeling of products viewed as environmentally friendly}

Currently, about $80 \%$ of foods available in U.S. supermarkets contain GM ingredients. Consumers have expressed some concerns about these foods, as evidenced by the recent GM 
166 Environmental and Economic Impact on Sustainable Development

labeling initiative that was voted down in California [14]. Manufacturers have responded to some of these concerns, and the number of GM-free labeled products available on the market increased by about 3,500 from 2000 to 2004 [15]. Large companies are beginning to not only cater to consumers' desire for organic or non-GMO products but to also echo these requests through support of labeling. Most recently, media reports shared that General Mills is producing their popular Cheerios cereal without GM-ingredients while Campbell Soup announced that it will begin listing all GM-ingredients and supporting labeling throughout the industry [16]. Currently, however, GM foods are still widely available for purchase without consistent labeling.

\section{EGOISTIC MOTIVATORS}

\subsection{Personal identification}

The connection between organic or sustainable goods and environmental concern is established in literature, but studies also suggest that the desire for environmental welfare may not be purely altruistic but also highly personal due to the identification element. Analysis of consumer interviews in Spain revealed that consumers identify organic foods as healthier, more safe, more natural, and overall superior products, which the authors refer to as a 'superiority heuristic'-implying that people purchase goods labeled "organic" not simply due to environmental concern but also because it is mentally viewed as a sign of superior products. Altruistic appeal is not merely rational but also emotional, and this dual perspective furthers the concept that food choice is driven by a combination of altruistic reasons-such as global welfare-and egoistic reasons - which includes personal identification as an ethical person, personal health, and nutrition [17]. The concept of ethical self-identity which predicted sustainable food purchases in the study by Dowd and Burke [9] also represents the duplicity of the altruistic-egoistic domain of ethical decision making.

\subsection{Personal preference}

For those who consume organic food, important factors include the naturalness, sensory features, and emotional experience related to these foods [18]. Consumers may relate the ethical origins of foods as such a positive factor that even these subjective preference measures may be effected. A cross-cultural study assessing consumer perspective on ethically produced tomato sauce found that those who rated the environmental benefits of organic sauce more highly also rated the probable taste of the product more highly $(\beta=.48, \mathrm{SE}=.02, \mathrm{p}<.001)$, revealing that the satisfaction that some consumers experience when choosing organic foods can lead to perceived preference for the food quality [19].

Interviews with organic-purchasing consumers revealed top characteristics associated with such products to be chemical-free, environmentally friendly production, and healthy qualities. These were ranked more highly than sensory features or natural qualities. When discussing the effects of choosing organic foods, the most notable responses were that they could improve health, were less harmful to nature than non-organic goods, and that they were high-quality goods. The findings were grouped into pathways of choice: 'living in accordance with nature'- which reflects altruism, 'usefulness to humans'- referring to taste and pleasure, and 'living a good quality lifestyle'- which reflects general qualities of healthy and chemical-free [20]. 


\section{IMPACT ON THE ENVIRONMENT}

There has been some controversy worldwide about whether or not the benefits of genetically modified foods outweigh the potential environmental impact of their production. Researchers have cited multiple factors of GMO cultivation that can lead to changes in the environment. One important environmental impact of GM foods is the threat to biodiversity resulting from the genetic transfer from GM crops to native plant species. Genes from GM crops can spread to wild types of the same crop, such as a gene from GM maize invading the genetic makeup of non-GM maize. This genetic transfer could cause GM genes to dominate, potentially wiping out the wild variety. Because of this, genetic diversity will greatly decrease, and the desirable traits from wild type crops will no longer be available because these varieties will no longer exist $[15,21]$.

\subsection{Addressing environmental issues}

One of the problems involved in addressing the environmental issues surrounding GM foods is that there is no universally accepted definition of what constitutes environmental damage or environmental harm. Because of this, it is difficult to assess the environmental safety of GM crops. Furthermore, the long-term environmental impacts of GM crops cannot yet be determined because these issues occur over time. When it comes to formulating opinions about GM foods, consumers place their trust the most in university scientists and farmers, followed by government agencies and environmental groups with a moderate trust level, and they place the least amount of trust in food producers and supermarkets. This could mean that if scientists and farmers conduct more studies regarding the negative environmental impacts of GM foods, then consumers may react more negatively towards these products. In turn, more focus might be placed on addressing these environmental issues.

\section{CONCLUSIONS}

Although GM-foods are very prevalent in the food system, the long-term environmental impacts of GM food production are still not completely known. Research currently shows that these crops may potentially have unknown long-term negative effects, such as threatening biodiversity and increasing the prevalence of herbicide and pesticide resistant weeds and pests [22]. The U.S. is the leader worldwide in GM food production, and these foods are readily available on supermarket shelves. If GM foods continue to dominate supermarket shelves in the U.S. and consumers continue to buy them, then there may be less pressure for the government to pass GM labeling regulations. Consumers repeatedly verbalize the desire for GMO labeling, particularly due to the inability to fully predict the effects of GMOs on the environment and consumer health. Future research can study the reasoning behind the differences in the marketing of non-GM foods in the supermarkets.

The current body of research highlights the complex nature of food choice. Both altruistic and egoistic values play a role in the decision to purchase organic or non-GMO food, with issues such as environmental safety, preservation, importance of global issues, health value, and sensory qualities all playing a role. While some studies show that altruistic messages weigh more heavily with consumers, others argue that even altruism is inherently egoistic due to the desired self-image associated with ethical decisions. It should also be noted that there is an ever-present risk of survey bias through which respondents choose responses that they feel are more positively received, such as that of heightened altruism. Even so, the influence of these two realms clearly plays a role in dictating food choice. 
168 Environmental and Economic Impact on Sustainable Development

Consumer attitude towards product categories provides great insight into their purchasing behaviors. Studies have shown strong correlations between consumer attitude toward non-GMO products and their actual purchases $(\mathrm{r}=0.701, \mathrm{p}<0.001)$, indicating that any insight into consumer beliefs and attitudes can reveal what they are likely to purchase [23]. With altruistic and egoistic values impacting attitude, they therefore likely also influence actual purchasing. Those who value the environmental safety of food production as well as the qualities of safely produced food may therefore be more likely to purchase such foods and support their desired method of production.

\section{REFERENCES}

[1] U.S. Food and Drug Administration, Questions \& answers on food from genetically engineered plants web site, Washington, DC, available at http://www.fda.gov/food/ foodscienceresearch/biotechnology/ucm346030.htm

[2] U.S. Food and Drug Administration, Difference between a dietary supplement and a conventional food web site, Washington, DC, available at http://www.fda.gov/aboutfda/ transparency/basics/ucm194357.htm

[3] U.S. Department of agriculture, National organic program web site, Washington, DC, available at http://www.ams.usda.gov/AMSv1.0/nop

[4] Turker, T., Kocak, N., Aydin, I., Istanbullouglu, H., Yildiran, N., Turk, Y.Z. \& Kilic, S., Determination of knowledge, attitude, behavior about genetically modified organisms in nursing school students. Gulhane Medical Journal, 55(4), pp. 297-304, 2013. http://dx.doi.org/10.5455/gulhane.33326

[5] Hallman, W., Hebden, W., Cuite, C., Aquino, H. \& Lang, J., Americans and GM food: knowledge, opinion \& interest in 2004, New Brunswick (NJ): Rutgers, the State University of New Jersey, Food Policy Institute; 2004 Nov Report No.: RR-1104-007, 2004.

[6] Aleksejeva, I., Latvian consumers' knowledge about genetically modified organisms. Management of Organizations: Systematic Research, 71, pp. 7-16, 2014. http://dx.doi.org/10.7220/mosr.2335.8750.2014.71.1

[7] Mielby, H., Sandoe, P. \& Lassen, J., The role of scientific knowledge in shaping public attitudes to GM technologies. Public Understanding of Science, 22(2), pp. 155-168, 2013. http://dx.doi.org/10.1177/0963662511430577

[8] Wunderlich, S. \& Gatto, K.A., Consumer perception of genetically modified organisms and sources of information. Advanced Nutrition, 13(6), pp. 842-851, 2015. http://dx.doi.org/10.3945/an.115.008870

[9] Dowd, K. \& Burke, K.J., The influence of ethical values and food choice motivations on intentions to purchase sustainably sourced foods. Appetite, 69, pp. 37-144, 2013. http://dx.doi.org/10.1016/j.appet.2013.05.024

[10] Kareklas, I., Carlson, J.R. \& Muehling, D.D., I eat organic for my benefit and yours: egoistic and altruistic considerations for purchasing organic food and their implications for advertising strategists. Journal of Advertising, 43(1), pp. 18-32, 2014. http://dx.doi.org/10.1080/00913367.2013.799450

[11] Worsley, A., Wang, W.C. \& Burton, M., Food concerns and support for environmental food policies and purchasing. Appetite, 91, pp. 48-55, 2015. http://dx.doi.org/10.1016/j.appet.2015.02.040

[12] Font, M.C., Mapping social and environmental concerns and the acceptability of genetically modified organisms in the European Union. The Journal of Social-Economics, 40(6), pp. 903-908, 2010. http://dx.doi.org/10.1016/j.socec.2011.08.014 
[13] Hudson, J., Caplanova, A. \& Novak, M., Public attitudes to GM foods. The balancing of risks and gains. Appetite, 92, pp. 303-313, 2015.

http://dx.doi.org/10.1016/j.appet.2015.05.031

[14] Martin, C., The psychology of GMO. Current Biology, 23(9), pp. R356-R359, 2013. http://dx.doi.org/10.1016/j.cub.2013.03.027

[15] van den Bergh, J.C. \& Holley, J.M., An environmental-economic assessment of genetic modification of agricultural crops. Futures, 34(9-10), pp. 807-822, 2002. http://dx.doi.org/10.1016/S0016-3287(02)00028-9

[16] Strom, S., Campbell will disclose G.M.O, ingredients, The New York Times, 7 Jan 2016.

[17] Vega-Zamova, M., Paras-Rosa, M., Murgado-Armenteros, E.A. \& Torres-Ruiz, F.J., The influence of the term 'organic' on organic food purchasing behavior. Procedia- Social and Behavioral Sciences, 81, pp. 660-671, 2013.

http://dx.doi.org/10.1016/j.sbspro.2013.06.493

[18] Lockie, S., Lyons, K., Lawrence, G. \& Grice, J., Choosing organics: a path analysis of factors underlying the selection of organic food among Australian consumers. Appetite, 43(2), pp. 135-146, 2014.

http://dx.doi.org/10.1016/j.appet.2004.02.004

[19] Bratanova, B., Vauclair, C.M., Kervyn, N., Schumann, S., Wood, R. \& Klein, O., Savouring morality. Moral satisfaction renders food of ethical origin subjectively tastier. Appetite, 91, pp. 137-149, 2015. http://dx.doi.org/10.1016/j.appet.2015.04.006

[20] Zagata, L., Towards conscientious food consumption: exploring the values of Czech organic food consumers. International Journal of Consumer Studies, 38(3), pp. 243-250, 2014. http://dx.doi.org/10.1111/ijcs.12098

[21] Pandey, P.P., Kumar, B.B. \& Tiwari, D.K., Environmental considerations concerning the release of genetically modified organisms. Proenvironment Promediu, 3(6), pp. 381-384, 2010.

[22] Rotolo, G.C., Francis, C., Craviotto, R.M., Viglia, S., Pereyra, A. \& Ulgiati, S., Time to re-think the GMO revolution in agriculture. Ecosystem Metabolism towards Sustainable Society Design and Management, 26(1), pp. 35-49, 2015.

[23] Vecchione, M., Feldman, C. \& Wunderlich, S., Consumer knowledge and attitudes about genetically modified food products and labeling policy. International Journal of Food Science and Nutrition, 66(3), pp. 329-335, 2015.

http://dx.doi.org/10.3109/09637486.2014.986072 